\title{
Permeation Rates of Electrolytic Hydrogen and Deuterium Through Iron
}

\author{
Joseph W. Pitts
}

(December 20, 1962)

\begin{abstract}
LTe relative permeation rates of electrolytically discharged hydrogen, deuterium, and mixtures of the two through sheet-iron cathodes were measured, and values for both the separation factor and the combined separation-permeation factor were determined. Also, data were obtained on the influence of strain, surface condition, and chemically precharged hydrogen on the permeation rate of electrolytic hydrogen.
\end{abstract}

\section{Introduction}

The hydrogen isotopes, deuterium and tritium, are frequently used as tracers in studies of various reactions involving ordinary hydrogen (protium). In many of these studies the $1: 2: 3$ mass ratio of the isotopes is inconsequential and can be ignored. But in rate processes such as diffusion the mass differences must be taken into account. The necessary adjustment of data can often be accomplished by calculations, especially when the diffusion or other process is well defined and understood. However, there are some kinetic processes in which use of the heavy isotopes of hydrogen as tagged atoms is limited because of the unknown effects of the mass differences. The passage of hydrogen through iron, for example, is not a pure diffusion process at ambient temperatures $[1 \mathrm{a}]^{1}$ and, despite a vast amount of research, the phenomenon is still not well understood. Hence, before results from tracer studies which involve the permeation of hydrogen through iron can be interpreted, the effect of the differences in mass must be determined experimentally.

The present paper gives the results of measurements of permeation rates of cathodic hydrogen and deuterium, and mixtures of the two, through commercially pure iron at $30^{\circ} \mathrm{C}$. In addition, the effects of metal roughness, cold work, and chemically precharged hydrogen on the permeation rates of cathodic hydrogen were studied.

\section{Experimental Procedure}

Normalized ingot-iron sheet of commercial purity was used for all tests. The sheet was temper rolled to have a slightly roughened surface. Major impurities in weight percent for an iron of this type are: $0.02 \mathrm{C}, 0.04 \mathrm{Mn}, 0.04 \mathrm{Cu}, 0.02 \mathrm{Ni}, 0.02 \mathrm{~S}$, and 0.07 O. Specimens were cut from sheet stock of several thicknesses and prepared as shown in table 1.

\footnotetext{
1 Figures in brackets indicate the literature references on page 117.
}

TABLE 1. Preparation of sheet iron specimens for measurement of hydrogen permeation

\begin{tabular}{|c|c|c|c|}
\hline Group & $\begin{array}{l}\text { Metal } \\
\text { thickness }\end{array}$ & Surface texture & Method of preparation \\
\hline $\begin{array}{l}A-1 \\
A-2\end{array}$ & $\begin{array}{l}m m \\
\quad 0.28 \\
1.26\end{array}$ & $\begin{array}{l}\text { Semismooth (finely } \\
\text { ground). }\end{array}$ & $\begin{array}{l}\text { Hand abraded on both sides under } \\
\text { water with No. } 600 \mathrm{SiC} \text { abrasive } \\
\text { paper. }\end{array}$ \\
\hline B & 0.28 & $\begin{array}{l}\text { Very rough (grit } \\
\text { blasted). }\end{array}$ & $\begin{array}{l}\text { Sandblasted on both sides with } \\
\text { No. } 60 \text { mesh silica sand at } 80 \text { psi. }\end{array}$ \\
\hline $\mathrm{C}$ & 1.07 & $\begin{array}{l}\text { Semismooth (finely } \\
\text { ground). }\end{array}$ & $\begin{array}{l}\text { Cold-rolled from } 1.83 \mathrm{~mm} \text { to } 1.07 \\
\text { mm thick ( } 42 \% \text { reduction) then } \\
\text { hand abraded as } \mathrm{A} \text { above. }\end{array}$ \\
\hline $\mathrm{D}$ & 0.28 & $\begin{array}{l}\text { Etched (acid } \\
\text { pickled). }\end{array}$ & $\begin{array}{l}\text { Pickled on both sides in } 7 \% \mathrm{H}_{2} \mathrm{SO}_{4} \\
\text { at } 70^{\circ} \mathrm{C} \text { for } 5 \mathrm{~min} \text {. }\end{array}$ \\
\hline $\mathrm{E}$ & .95 & $\begin{array}{l}\text { Thermally etched, } \\
\text { bright annealed. }\end{array}$ & $\begin{array}{l}\text { Coated on both sides with non- } \\
\text { adhering enamel glass, heated } \\
\text { to annealing temperature, air } \\
\text { cooled. }^{\text {a }}\end{array}$ \\
\hline
\end{tabular}

a This process for cleaning and heat-treating metals is similar to common porcelain enameling, except that the enamel composition and the processing techniques are designed to give a nonadherent coating [16]. The metal is heated in air to the fusion temperature of the coating $\left(870^{\circ} \mathrm{C}\right.$ in the present case) and held for about 5 to $10 \mathrm{~min}$ while the molten enamel selectively attacks the metal surface and dissolves oxides and other curface impurities. composite The resulting metal surface is deeply etched, but retains a bright metallic appearance.

The iron was cathodically charged with hydrooen by electrolyzing $1.0 \mathrm{~N}$ orthophosphoric acid. This acid was selected because it can be conveniently prepared by mixing $\mathrm{P}_{2} \mathrm{O}_{5}$ with either $\mathrm{H}_{2} \mathrm{O}$ or $\mathrm{D}_{2} \mathrm{O}$ to yield either $\mathrm{H}_{3} \mathrm{PO}_{4}$ or $\mathrm{D}_{3} \mathrm{PO}_{4}$, respectively. The heavy water used for making the $\mathrm{D}_{3} \mathrm{PO}_{4}$ was 99.8 percent $\mathrm{D}_{2} \mathrm{O}$.

Figure 1 is a schematic drawing of the apparatus used for producing the atomic hydrogen and measuring its permeation through iron specimens; the apparatus is similar to that used by Dietzel and Stegmaier [2]. Each experiment was started with a fresh quantity of electrolyte and a new specimen. 


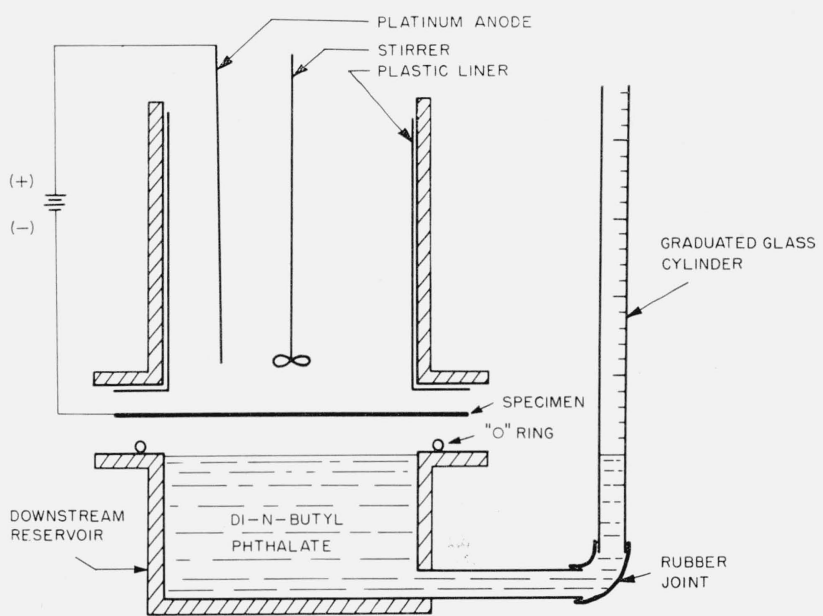

Figure 1. A schematic drawing of the hydrogen permeation apparatus.

The cell was prepared for use by bolting the two sections together and tilting to expel trapped air. The apparatus was then partially submerged in a temperature-controlled water bath.

Experiments were conducted at a temperature of $30^{\circ} \pm 0.5^{\circ} \mathrm{C}$ and at a cathode current density of $5 \mathrm{ma} / \mathrm{cm}^{2}$. The area of the platinum anode was 150 $\mathrm{cm}^{2}$ and the area of the cathode was $31 \mathrm{~cm}^{2}$. The electrolytes were continuously and vigorously stirred throughout the experiments which lasted for periods of from 3 to $30 \mathrm{hr}$. Electrolysis was stopped after the permeation rate had reached a steady-state value or had passed through a maximum value. Rates were determined at frequent time intervals from the cumulative volume measurements of hydrogen permeating a specimen, as indicated by the volume of di-n-butyl phthalate displaced into the graduated cylinder. The accuracy of this measurement was of the order of $\pm 0.01 \mathrm{ml}$.

\section{Reproducibility of Measurements}

Several investigators of the permeation of cathodic hydrogen through iron have been concerned with reproducibility and have sought means of improving it. Heller [3] discussed reasons for the difficulties involved in making quantitative measurements. Duflot [4] established that electrolytic polishing of iron greatly improves the reproducibility of occlusive capacity measurements; however, Robertson [3] was unable to confirm this finding. Lagasse and Lilet [5] observed that permeation rates continuously decreased as a function of time in experiments incorporating the common technique of adding catalytic "poisons" 2 to acid electrolytes in a cell containing a passive anode such as platinum. In order to obtain steady-state flow and to create reproducible experi-

\footnotetext{
2 The evolution of gaseous hydrogen from an electrolyte is believed to be a two-stage process: (1) the discharge of hydrogen ions at the cathode, and (2) the two-stage process: (1) the discharge of hydrogen ions at the cathode, and (2) the
formation of molecular from atomic hydrogen. The latter step is aided by the formation of molecular from atomic hydrogen. The latter step is aided by the catalytic effect of the iron surface; however, small quantities of certain elements
of Groups V and VI (P, As, S, Se, etc.) inhibit this catalysis and are said to of Groups V and VI ( $\mathrm{P}$, As, S, Se, etc.) inhibit this catalysis and are said to atomic hydrogen facilitates its entry into the metal [6].
}

mental conditions, these investigators devised a novel approach which produced not only a uniform flow of hydrogen but also a ten-fold increase in total flux over that obtainable by any previous method. They used a consumable carbon anode which they believed indirectly modified the excess hydrogen overvoltage at the cathode thus increasing the permeation rate. Also, the carbon anode contained the catalytic poisons, arsenic and selenium, which were liberated while the anode was being expended; thus, a continuous and fresh supply of catalytic poison was available throughout the duration of an experiment.

In the present experiments the acid was poisoned with $1 \mathrm{~g}$ per liter of $\mathrm{As}_{2} \mathrm{O}_{3}$. This amount of arsenic appeared to be sufficient to produce and maintain a uniform flow of hydrogen through the cathode. Also, the permeation rates obtained were entirely adequate for obtaining accurate measurements; however, the reproducibility was such as to require many replicate determinations in order to obtain averages with reasonably low statistical uncertainty. Poor reproducibility was believed to be attributable to very small differences in either surface texture and/or internal structure of specimens that were supposedly identical.

\section{Effects of Different Specimen Preparation Techniques}

Several variables in specimen preparation were investigated prior to the measurement of relative permeation rates of hydrogen and deuterium. These screening tests were made with ordinary hydrogen. The results, in the next three sections, are presented and discussed primarily for their qualitative value.

\subsection{Effect of Cold Work}

A number of investigators have studied the effects of cold work on the permeation of hydrogen through iron and steel and have reported differing results; some have found that permeation continuously decreases with increasing cold work and some have reported just the opposite effect. However, the apparent discrepancies may be the result of different starting materials and different testing conditions. The more recent research indicates that the permeation rate initially increases with increasing cold work and then, after reaching a maximum rate, decreases with further cold work. In 1953 Schumann and Erdman-Jesnitzer [7] first reported that permeation increases with cold work up to a maximum of 10 to 20 percent reduction in thickness of the metal; above this range, specimens with further increasing amounts of cold work display progressively lower permeabilities. At least two other investigators $[5,8]$ have since reported similar results.

In the present investigation sheet iron was cold rolled to 42 percent reduction in thickness and its permeability compared to that of normalized sheet. Specimens were prepared as described in table 1 (Groups $\mathrm{A}-1, \mathrm{~A}-2$, and $\mathrm{C}$ ), and the permeation rate 


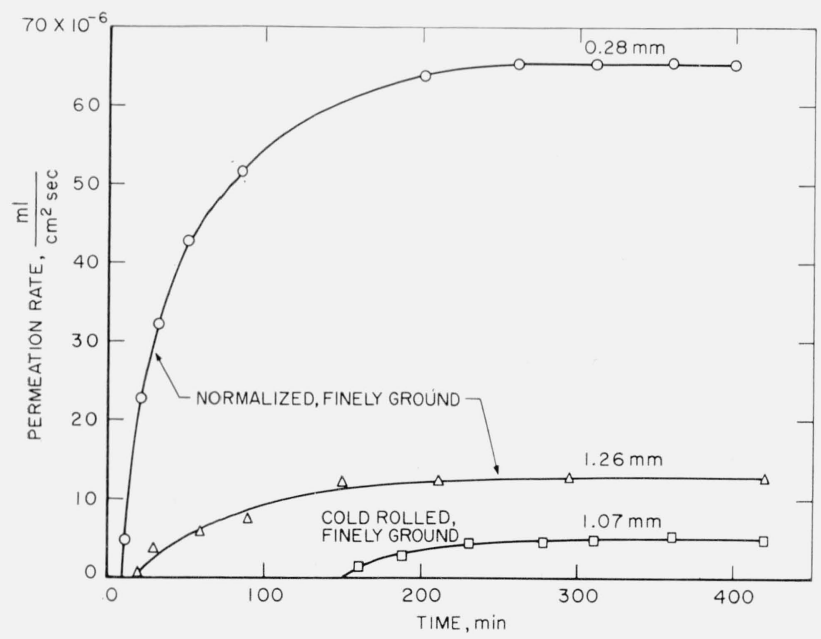

FIGURE 2. The effect of cold rolling on the permeability of iron to hydrogen.

The permeation rate is expressed as the number of milliliters of hydrogen at $30^{\circ} \mathrm{C}$ and $1 \mathrm{~atm}$ pressure permeating in $1 \mathrm{sec}$ an area of $1 \mathrm{~cm}^{2}$ of a specimen of the indicated thickness.

measurements of single specimens which are typical of each group are shown in figure 2 . It can be seen that the permeability of cold rolled specimens, $1.07 \mathrm{~mm}$ thick, was much less than the permeability of normalized specimens, 0.28 and $1.26 \mathrm{~mm}$ thick. This great reduction in permeation caused by cold work is qualitatively in agreement with the results of the investigators cited above.

\subsection{Effect of Surface Roughness}

Roughened surfaces were produced by sandblasting, and the effect of this treatment on cathodic permeation was determined. The result is shown in figure 3.

Sandblasting not only roughens the surface but also produces some cold work. The cold work extends only a short distance below the surface of the metal; however, the surface zone is severely distorted, and it may be assumed that the outermost layers are deformed far beyond the 10 to 20 percent range that Schumann and Erdman-Jesnitzer found to contain the turning point from increased to decreased permeation. If so, it could be that this cold-worked zone provides the slow and rate-limiting step in the overall permeation process.

On the other hand, the observed reduction in permeation is in agreement with the statement of Evans [6] that "rough surfaces are less liable to the entry of hydrogen into the metal than smooth ones, doubtless because they provide points favorable to the conversion of atomic to molecular hydrogen." Molecular hydrogen does not enter the metal but collects into bubbles and escapes from the electrolyte; therefore, anything that inhibits the formation of molecular hydrogen, such as for example catalytic poisons or smooth surfaces, favors the infusion of hydrogen into the metal.

In apparent contrast to the above, Hudson and coworkers [9], and Smithells and Ransley [10] re-

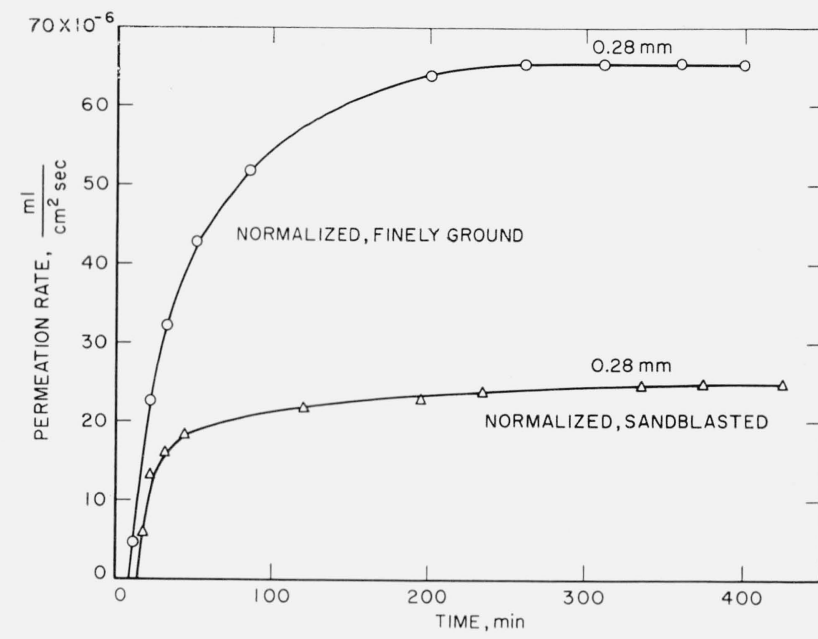

FIGURE 3. The effect of sandblasting on the permeabitity of iron to hydrogen.

ported the opposite effect of surface roughness. However, in both of these cases the experimental procedures were different from cathodic charging, and involved different mechanisms of hydrogen infusion. Hudson found that roughening the surface by sandblasting increased the rate of hydrogen absorption during acid pickling. The increased rate probably can be attributed to the strain energy of the sandblasted surface, which undoubtedly affects pickling behavior. Furthermore, the severely cold-worked zone may have been substantially etched away during pickling.

Smithells and Ransley [10] measured the permeation of hydrogen at $673^{\circ} \mathrm{C}$ and $0.77 \mathrm{~mm} \mathrm{Ho}$ pressure and found that the permeation rate through polished iron specimens was increased 10 -fold by acid etching. Under these conditions the increased permeation rate probably resulted from the increased surface area provided by the etching.

The present sandblasting experiment did not separate the effects of cold work and surface roughness; consequently, no conclusion can be drawn as to which is more effective in reducing hydrogen permeation. However, another experiment (sec. 4.3b) in which surfaces were roughened by chemical etching, did confirm that roughness, alone, decreases the permeation of electrolytic hydrogen.

\subsection{Effect of Prior Charging}

Inasmuch as surface condition is known to affect the entry of hydrogen into iron, an attempt was made to study this effect with specimens having. metallurgically "clean" and strain-free surfaces. Specimens were prepared by both acid pickling and by the ceramic coating-bright annealing technique (Groups D and E table 1). It was known that both methods inherently result in the uptake and retention of hydrogen in iron, but it was not known what effect this precharged hydrogen would have on subsequent electroly tic charging. Figure 4 compares 


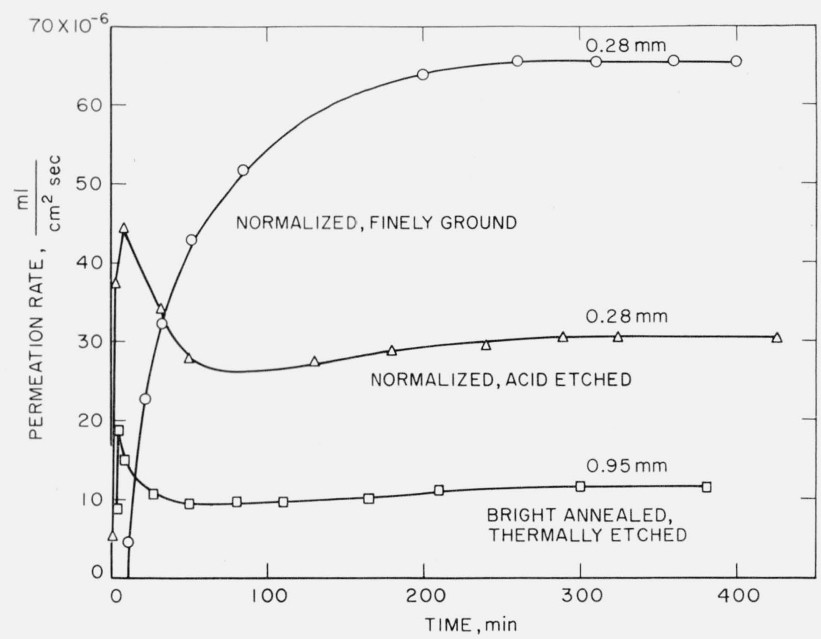

FIgure 4. The effects of acid pickling and ceramic coatingbright annealing on the permeability of iron to electrolytic hydrogen.

the permeabilities of specimens prepared by these two methods with the permeability of a normalized finely ground specimen. This figure shows that the hydrogen permeation rate through a prior-charged specimen (acid pickled or ceramic coated), quickly reached a maximum value then dropped to a lower steady-state value; in contrast, the normal condition is for the rate to start low and gradually increase until a steady state is reached. This initial abnormal behavior of the prior-charged specimens is undoubtedly due to diffusible occluded hydrogen, which rapidly becomes activated when hydrogen pressure from electrolysis is applied to the specimens.

\section{a. Ceramic Coating}

It has been shown in porcelain enameling technology [11] that, at the firing temperature, iron becomes saturated with hydrogen made available by the chemical reaction of water dissolved in the glass with the hot iron, and the metal subsequently becomes supersaturated with hydrogen when it is cooled to room temperature. Some of this occluded hydrogen may diffuse out of the iron, eventually building up enough pressure at the iron-enamel interface to fracture the enamel. The same conditions were present with the ceramic-annealed specimens except that the hydrogen was not restrained from diffusing out.

It is probable that a substantial fraction of the occluded hydrogen escaped from the iron specimens between the time they were precharged and the time that electrolytic permeation measurements were made. This time delay varied from 2 to 120 days and, surprisingly, the length of the delay had no significant effect on the permeation behavior. This fact seems to indicate that the quantity of precharged hydrogen in iron remains fairly constant after the first 48-hr holding period.
Inasmuch as structure and surface are both affected by ceramic annealing, the cause of the reduction in steady-state permeation could not be determined. The resistance of the metal structure to the passage of hydrogen undoubtedly was altered by the annealing process, but also the surface was roughened as a result of selective dissolution of metal grains by the enamel.

\section{b. Acid Pickling}

Acid pickling roughens the metal surface but has no effect on the internal structure (other than introducing hydrogen). Therefore, it appears that the reduction in steady-state permeation is the result of the aforementioned catalytic effect of rough surfaces.

The steady-state rates of both the acid-pickled and ceramic-annealed specimens could be varied by changing the conditions of precharging; also, the heights of the peaks shown in figure 4 varied greatly even among replicate tests. However, the relative positions of these curves with respect to the normal curve remained unchanged.

\section{c. Surface Abrading}

Frank and Swets [12] found that hydrogen entered and diffused through steel when the metal was rubbed with abrasive paper. The effect could be detected and measured with a mass spectrometer even when dry abrasive paper was used; however, a vastly greater flow rate was obtained when the paper and specimen were wet. But the maximum flow rate observed by this method is smaller by a factor of at least $10^{3}$ than that obtainable by acid electrolysis.

The specimens prepared as described in table 1 , Group A probably contained some precharged hydrogen from this source despite great care to prevent rusting, yet apparently the amount of hydrogen precharged by abrading was too small to affect subsequent electrolytic charging. This was confirmed experimentally by abrading two groups of specimens identically except that water was used for one group and carbon tetrachloride for the other; there was no significant difference between the permeation rates of the two groups.

\section{Results and Discussions of Hydrogen- Deuterium Permeation}

The solid-line curve in figure 5 shows the steadystate permeation rate measurements of hydrogen, deuterium, and mixtures of the two plotted as a function of the percent of $\mathrm{D}_{3} \mathrm{PO}_{4}$ in the $\mathrm{D}_{3} \mathrm{PO}_{4}+\mathrm{H}_{3} \mathrm{PO}_{4}$ electrolvte. The dashed line is a theoretical curve and is discussed in section 5.3. Each point plotted on the graph is the average of six or more specimens prepared as shown in table 1 , group $\mathrm{A}-1$. The standard deviations about the respective means are indicated by vertical lines at the points.

The fact that the curve is concave downward is significant and can be readily explained on the basis of the deuterium enrichment phenomenon (separa- 


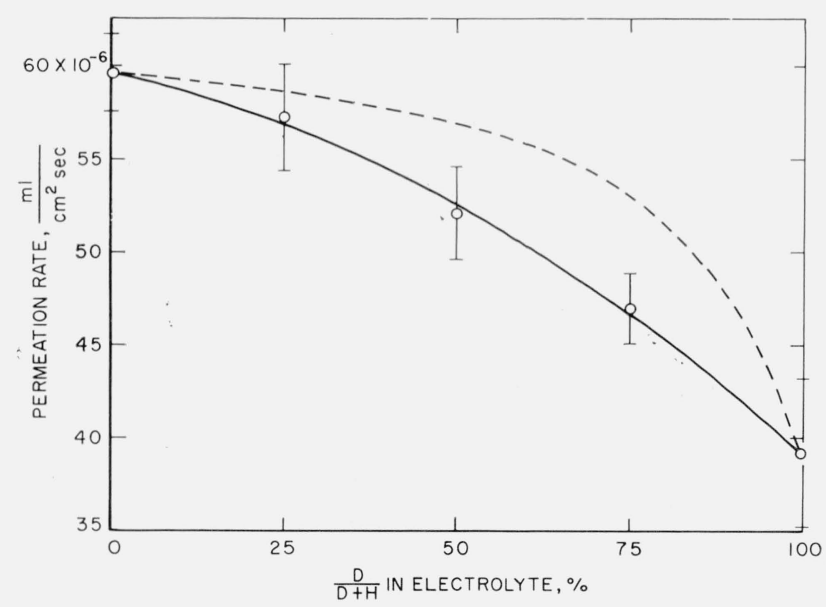

Figure 5. The steady-state permeation rates of mixtures of hydrogen and deuterium permeating $0.28 \mathrm{~mm}$ thick iron specimens as a function of the percent of $\mathrm{D}_{3} \mathrm{PO}_{4}$ in the total $\mathrm{D}_{3} \mathrm{PO}_{4}+\mathrm{H}_{3} \mathrm{PO}_{4}$ electrolyte.

tion factor). The separation factor is defined as the ratio of hydrogen to deuterium in the gas liberated at the cathode divided by the ratio of hydrogen to deuterium in the electrolyte.

$$
\text { Thus, } S=\frac{(\mathrm{H} / \mathrm{D})_{\text {gas }}}{(\mathrm{H} / \mathrm{D})_{\text {soln }}}
$$

The separation factor is dependent on a number of experimental conditions; consequently, a range of values can be found in the literature. Bockris [13] reported that at room temperature and at a current density of $1 \mathrm{amp} / \mathrm{cm}^{2}, S=5$ to 10 in a $1 N$ aqueous acid or alkaline solution.

\subsection{Discussion of the Rate-Concentration Curve}

Although this preferential discharge of hydrogen at the cathode may appear to be an adequate explanation of the results plotted in figure 5, there are other possible contributing effects. It is well established that the abundance of hydrogen at the cathode signifies little with regard to its rate of infusion into the metal (the prime example, obviously, is the above-mentioned effect of catalysis). Also, one must consider the mobilities of the two isotopes, once they enter the metal, and the influence that the presence of each has on the other. One of the several theories of hydrogen behavior is that the crystal structure of iron becomes "opened" when hydrogen under pressure, such as by cathodic charging, is forced into the structure; i.e., the passage of hydrogen through the structure creates lattice "rifts" which then facilitate further passage of the gas. Smith [1b] in commenting on the relative solubilities of hydrogen and deuterium in iron as reported by Sieverts et al., [14] noted that the observation of the solubility of deuterium was in each instance preceded by a measurement of the solubility of hydrogen, a procedure which may very well have increased the permeability and capacity of the metal for deuterium. Also, in the case of palladium, Smith [1c] further states that "the more penetrative hydrogen is capable of opening up the metal so that it is afterward readily permeable to deuterium."

In light of the above, it is conceivable that the shape of the experimental rate-concentration curve (fig. 5) is influenced by interactions between the two isotopes after being discharged from the electrolyte; consequently, this possibility was explored.

\subsection{Separation Factor and Separation-Permeation Factor}

The discharged gases, both before and after permeation through the iron, were analyzed in order to determine quantitatively the separation factor and the combined effect of the separation factor and the permeation rates of mixtures of the two isotopes. The term "separation-permeation factor," $S-P$, was used to express this combined effect and is defined as the ratio of hydrogen to deuterium in the permeated gas divided by the ratio of hydrogen to deuterium in the electrolyte. Thus,

$$
S-P=\frac{(\mathrm{H} / \mathrm{D})_{\text {perm. gas }}}{(\mathrm{H} / \mathrm{D})_{\text {soln }}} .
$$

The gases that diffused through the iron were collected for analysis in either of two ways: (1) the downstream reservoir was filled with di-n-butyl phthalate as described earlier and the diffusant, after displacing the di-n-butyl phthalate and bubbling up through the liquid into the graduated cylinder, was transferred to an evacuated sampling container, or (2) the downstream reservoir was emptied and connected directly to the sampling container and both were evacuated prior to starting diffusion. One sample of undiffused gas was collected from the electrolyte side of the cathode for determination of the separation factor. In this case, the electrolyte chamber was connected to a closed system that was initially outgassed.

The results of the mass-spectrometer analyses of these various samples, together with the computed separation-permeation factors, are shown in table 2 . The results of the first three tests are considered approximate because of probable errors in the stated compositions of the electrolytes. Some hydrogen contamination of the $\mathrm{D}_{3} \mathrm{PO}_{4}$ undoubtedly occurred during the preparation of the acid because of the extreme hygroscopic nature of $\mathrm{P}_{2} \mathrm{O}_{5}$; also, the electrolytes were exposed to the open atmosphere during. electrolysis ( 8 to $12 \mathrm{hr}$ ).

In contrast, special precautions were taken to prevent contamination of the electrolyte by atmospheric moisture in Test No. 4, and because this electrolyte was near the composition midpoint, the experimentally determined values of the separation factor and the combined separation-permeation factor are mathematically the least sensitive of the four tests to errors in composition. Also, the composition of electrolyte No. 4 was adjusted to correct for the slight change that occurred during electrolysis. 
TABLE 2. Analyses of the gases originating from electrolytes of different compositions and the respective separation factor and separation-permeation factors

\begin{tabular}{|c|c|c|c|c|c|}
\hline Test No. & $\begin{array}{l}\mathrm{H}: \mathrm{D} \text { in } \\
\text { electrolyte }\end{array}$ & $\begin{array}{c}\mathrm{H}: \mathrm{D} \text { of } \\
\text { gas liberated } \\
\text { at cathode }\end{array}$ & $\begin{array}{l}\text { Separation } \\
\text { factor }(S)\end{array}$ & $\begin{array}{c}\mathrm{H}: \mathrm{D} \text { of } \\
\text { permeated } \\
\text { gas }\end{array}$ & $\begin{array}{l}\text { Separation- } \\
\text { permeation } \\
\text { factor } \\
(S-P)\end{array}$ \\
\hline $\begin{array}{l}1 \\
2 \\
3 \\
4\end{array}$ & $\begin{array}{c}\text { Atomic } \\
\text { percent } \\
\text { 1.0:99. } 0 \\
13.3: 86.7 \\
25.7: 74.3 \\
48.6: 51.4\end{array}$ & $\begin{array}{l}\text { Atomic } \\
\text { percent } \\
\text { (a) } \\
\text { (a) } \\
\text { (a) } \\
86.0: 14.0\end{array}$ & $6.5 \pm 0.15$ & $\begin{array}{c}\text { Atomic } \\
\text { percent } \\
9.2: 90.8 \\
\mathrm{~b} 65.8: 34.2 \\
79.1: 20.9 \\
90.0: 10.0\end{array}$ & $\begin{array}{r}10.0 \\
12.4 \\
10.9 \\
9.5 \pm 0.2\end{array}$ \\
\hline
\end{tabular}

a Not determined.

b This sample of gas was collected at atmospheric pressure over di- $n$-butyl phthalate; all others were collected at reduced pressures in evacuated chambers.

\subsection{Calculation of the Theoretical Rate- Concentration Curve}

If there are no side effects resulting from interactions of the two isotopes and if the separation factor is constant, it is possible to calculate the permeation rate which would be obtained from any initial mixture, when the value of the separation factor and the two terminal permeation rates are known. Thus, it can be shown that the permeation rate, $R$, of the mixture of gases yielded by any ratio of the isotopes in the electrolyte is given by

$$
R=m \frac{100 V}{V+S(100-V)}+c
$$

where $V=$ percent concentration of deuterium in the electrolyte, $m=$ slope of straight line joining the terminal rates, and $c=$ permeation rate of hydrogen (see app. for derivation).

The theoretical curve is drawn as a dashed line in figure 5, and it is apparent that this curve is significantly different from the experimental curve. The fact that the latter lies below the former indicates that a net retarding effect results when the two isotopes are mixed. Had the experimental curve been displaced above the theoretical curve, the interpretation would be that there was a net accelerating effect; i.e., that the presence of the hydrogen opens up the structure or otherwise speeds up the passage of deuterium without itself being proportionately slowed.

It was assumed that the separation factor was constant at all concentrations, but if $S$ is not constant, the shape of the theoretical curve would be different from that shown in figure 5. Bockris and Koch [15] have calculated the separation factor for iron as a function of $(\mathrm{H} / \mathrm{D})_{\text {soln }}$ from measurements of the exchange current densities of $\mathrm{HCl}$ and $\mathrm{DCl}$ solutions. These authors concluded that $S$ is nearly constant from zero to about 70 percent deuterium, but above 70 percent deuterium, $S$ decreases as deuterium increases. The effect of such behavior of the separation factor on the theoretical curve would be to reduce the divergence between it and the experimental curve above 70 percent deuterium; obviously, this effect would weaken the interpretation given in the preceding paragraph.

\subsection{Significance of the Separation-Permeation Factor}

It can be shown that if there are no side effects from interactions between the two isotopes, the separation-permeation factor is equal to the product of the separation factor and the ratio of the $\mathrm{H}$ and $\mathrm{D}$ terminal permeation rates. Thus,

$$
S-P=S \frac{R_{H}}{R_{D}}
$$

Inserting the value of $S$ from Test No. 4 and the terminal rates from figure 5

$$
S-P=6.5 \frac{59.6}{39.2}=9.9 \text {. }
$$

However, the experimental value of $S-P$ (from Test No. 4) was found to be 9.5. While the difference in these two values may not be significant, it is in the right direction to indicate that the overall reduction in rate is suffered at the expense of hydrogen.

\subsection{Limitation on Interpretation of Results}

The conclusions from these experiments are necessarily tentative for three reasons: (1) the $S$ and $S-P$ values are from a single test, (2) $S$ may vary at high deuterium concentrations, and (3) the deuterium terminal composition was not actually 100 percent but probably nearer 99 percent as a result of the previously mentioned contamination of the 99.8 percent starting material. If it is true that hydrogen tends to open the metal structure more than deuterium, then it is conceivable that a small fraction of hydrogen, even on the order of a few ppm, could have a significant effect on the apparent deuterium permeation rate. Thus, the rate for very pure deuterium could be much less than that of the impure material $(99+\%)$ which would have the effect of bringing the calculated curve of figure 5 closer to the experimental curve and invalidating all calculations based on the observed deuterium terminal permeation rate.

\section{Summary and Conclusions}

1. The permeation rates through iron of mixtures of hydrogen and deuterium discharged from acid electrolytes were found to be consistently lower than the calculated rates based on the relative availabilities of the two isotopes and the values of their individual permeation rates. The discrepancy was attributed to interference with the hydrogen by the heavier, slower deuterium within the iron structure, resulting in a net retardation.

2. The separation-permeation factor, which is a measure of the preferential discharge and permeation of hydrogen with respect to deuterium, gave a clue to the mechanism of the overall reduction in permeation rate. Although not rigidly conclusive, the indi- 
cation was that the flow of hydrogen, whether or not it increases the flow of deuterium, as has been postulated, is itself disproportionately interfered with by the presence of the latter.

3. The recent findings of previous investigators that severe cold work and surface roughness reduce permeation of cathodic hydrogen were confirmed; however, where both conditions prevailed simultaneously, there was doubt as to which had the greater effect.

4. Iron containing substantial amounts of hydrogen, precharged either by acid pickling or by porcelain enameling, displayed higher initial cathodic permeation rates but lower steady-state rates. Precharging iron with very small amounts of hydrogen by abrasion under water did not affect electrolytic permeation.

\section{References}

[1] D. P. Smith, Hydrogen in metals (The University of Chicago Press, Chicago, Ill.), (a) pp. 57-58, (b) p. 49, and (c) p. 116 (1948).

[2] A. Dietzel and W. Stegmaier, Tentative enamel testing methods (in German), Ber. deut. keram. Ges. u. Ver. deut. Emailfachleute, 29, pp. 132-137 (1952).

[3] W. R. Heller, Hydrogen in iron and its alloys, ch. 12 in Stress corrosion cracking and embrittlement, pp. 163-175, W. D. Robertson, ed. (John Wiley \& Sons, New York, N.Y., 1956).

[4] J. Duflot, Contribution to the study of supersaturation of iron by cathodic hydrogen (in French), Publications scientifiques et techniques, No. 265, Ministère de L'air (France) (1952).

[5] P. E. Lagasse and L. Lilet, Application of a practical method for measuring the diffusion of hydrogen through thin mild steel sheet (in French), Mem. Sci. de la Rev. de Met. 5\%, pp. 729-740 (1960).

[6] U. R. Evans, The corrosion and oxidation of metals, pp. 394-401 (Edward Arnold, Ltd., London, 1960).

[7] H. Schumann and F. Erdmann-Jesnitzer, Influence of cold work on hydrogen diffusion in unalloyed steel (in German), Arch. Eisenhuttenw. 24, pp. 353-60 (1953).

[8] (a) R. M. Hudson, K. J. Riedy, and G. L. Stragand, Influence of cold work on hydrogen behavior in steel, Corrosion 16, pp. 115t-118t (1960).

(b) R. M. Hudson and G. L. Stragand, Effect of cold drawing on hydrogen behavior in steel, Corrosion 16, pp. 253t-257t (1960).

(c) R. M. Hudson, M. Kotyk, and G. L. Stragand, Influence of cold-reduction practice on hydrogen behavior in enameling steels, J. Am. Ceram. Soc. 43, pp. $564-570(1960)$.

[9] R. M. Hudson, K. J. Riedy, and G. L. Stragand, Influence of specimen geometry and surface roughness on hydrogen behavior in steel, Corrosion 18, pp. 79t-84t (1962).

[10] C. J. Smithells and C. E. Ransley, The diffusion of gases through metals, Proc. Roy. Soc. (London), $150 \mathrm{~A}$, p. $172(1935)$.

[11] D. G. Moore, M. A. Mason, and W. N. Harrison, Relative importance of various sources of defectproducing hydrogen introduced into steel during the application of porcelain enamels, J. Am. Ceram. Soc. 35, pp. 33-41 (1952).

[12] R. C. Frank and D. E. Swets, Hydrogen permeation through steel during abrasion, J. Applied Phys. 28, p. 380 (1957)

[13] J. O’M. Bockris, Modern aspects of electrochemistry, Vol. I, p. 249, (Academic Press, Inc., New York, 1954)

[14] A. Sieverts, G. Zapf, and H. Moritz, Solubility of hydrogen, deuterium, and nitrogen in iron (in German), Z. Physik. Chem. [A] 183, pp. 19-37 (1938).
[15] J. O'M. Bockris and D. F. A. Koch, Comparative rates of the electrolytic evolution of hydrogen and deuterium on iron, tungsten, and platinum, J. Phys. Chem. 65, pp. 1941-1948 (1961).

[16] J. V. Long and J. V. Furth, Coating for cleaning and protecting metals, U.S. Patent 2,889,238 (1959).

\section{Appendix}

Derivation of an equation for calculating the combined permeation rate through an iron cathode of hydrogen and deuterium liberated from an electrolyte containing a mixture of the two isotopes. Given : Separation factor and individual permeation rate of each of the two isotopes.

If $S$ (the separation factor) $=1$, then all values of $R$ (the permeation rate) would be expected to fall on a straight line connecting the two terminal points and could be expressed mathematically by an equation of a straight line:

where

$$
R=m x+c
$$

$R=$ ordinate on a coordinate plot, as in figure 5.

$m=$ slope of the line joining the points.

$x=$ percentage concentration of one isotope (increasing along the abscissa from 0 at the origin).

$c=$ permeation rate of the other isotope $(R$-axis intercept).

But if $S \neq 1$, then by definition the hydrogendeuterium concentration at the cathode is different from the bulk concentration and the two are related thus:

$$
\frac{\mathrm{H}_{c}}{\mathrm{D}_{c}}=S \frac{\mathrm{H}}{\mathrm{D}}
$$

where $\frac{\mathrm{H}_{c}}{\mathrm{D}_{c}}$ is the concentration ratio at the cathode,

and $\frac{\mathrm{H}}{\mathrm{D}}$ is the bulk concentration ratio.

Let

$u=$ the concentration of deuterium at the cathode in percent

$V=$ the bulk concentration of deuterium in percent

$100-V=$ the bulk concentration of hydrogen in percent

then

$$
\begin{aligned}
u=\frac{100 \mathrm{D}_{c}}{\mathrm{D}_{c}+\mathrm{H}_{c}}=\frac{100 \frac{\mathrm{D}_{c}}{\mathrm{H}_{c}}}{1+\frac{\mathrm{D}_{c}}{\mathrm{H}_{c}}}=\frac{100 \frac{\mathrm{D}}{S \mathrm{H}}}{1+\frac{\mathrm{D}}{S H}} \\
=\frac{100 \mathrm{D}}{\mathrm{D}+S \mathrm{H}}=\frac{\frac{100 \mathrm{D}}{\mathrm{D}+\mathrm{H}}}{\frac{\mathrm{D}}{\mathrm{D}+\mathrm{H}}+\frac{S \mathrm{H}}{\mathrm{D}+\mathrm{H}}}
\end{aligned}
$$




$$
\begin{gathered}
V=\frac{100 \mathrm{D}}{\mathrm{D}+\mathrm{H}} \\
100-V=\frac{100 \mathrm{H}}{\mathrm{D}+\mathrm{H}}
\end{gathered}
$$

by substituting $\frac{\mathrm{D}}{\mathrm{D}+\mathrm{H}}$ and $\frac{\mathrm{H}}{\mathrm{D}+\mathrm{H}}$ from eq (4) and (5) into eq (3)

$$
u=\frac{100 V}{V+S(100-V)}
$$

Then by substituting $u$ for $x$ in eq (1) above, the general equation becomes

$$
R=m \frac{100 V}{V+S(100-V)}+c
$$

and inserting the experimental values

$$
\begin{aligned}
m & =-0.204 \\
S & =6.5
\end{aligned}
$$

$c=59.6$

eq (7) reduces to the equation of the dashed curve in figure 5 .

$$
R=59.6-\frac{20.4 \mathrm{~V}}{650-5.5 \mathrm{~V}}
$$

(Paper 67C'2-124) 